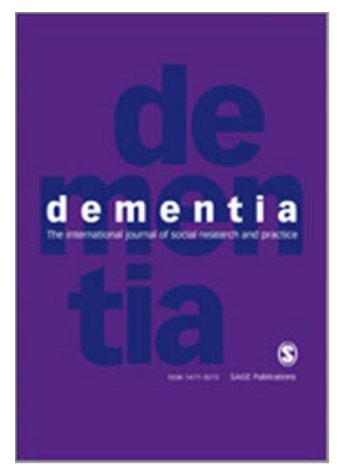

\title{
Visioning change: Co-producing a model of involvement and engagement in research.
}

\begin{tabular}{|r|l|}
\hline Journal: & Dementia: the international journal of social research and practice \\
\hline Manuscript ID & DEM-16-0114.R1 \\
\hline Origin of Contribution: & UK/Europe and the rest of the world \\
\hline Manuscript Type: & Innovative Practice \\
\hline Keywords: & Dementia, Involvement, Engagement, Co-production, Co-research \\
\hline & $\begin{array}{l}\text { The involvement of people living with dementia in research has } \\
\text { traditionally been located in the realms of 'subject' or 'participant'. } \\
\text { However, there has been an increase in demand for greater transparency } \\
\text { by academic bidding teams (particularly within the UK) in demonstrating } \\
\text { how people with a lived experience have been and will be involved in the } \\
\text { research process. Located within the ESRC / NIHR-funded Neighbourhoods } \\
\text { and Dementia Study (2014-2019), led by The University of Manchester } \\
\text { (UK), this paper outlines the development of the CO-researcher } \\
\text { INvolvement and Engagement in Dementia (COINED) Model, which was co- } \\
\text { produced alongside three independent groups of people living with } \\
\text { dementia: Open Doors, the Scottish Dementia Working Group and } \\
\text { EDUCATE. }\end{array}$ \\
\hline
\end{tabular}




\section{Title page}

Visioning change: Co-producing a model of involvement and engagement in research. (Innovative Practice)

Journal: Dementia: the international journal of social research and practice:

Innovative Practice

Authors: Caroline M Swarbrick ${ }^{1}$, Open Doors ${ }^{2}$, Scottish Dementia Working Group ${ }^{3}$, EDUCATE ${ }^{4}$, Davis $\mathrm{K}^{1}$. and Keady $\mathrm{J}^{5}$.

Corresponding author: Caroline M Swarbrick, Dementia and Ageing Research Team, School of Nursing, Midwifery and Social Work, Jean McFarlane Building, University of Manchester, Manchester, M13 9PL, UK

Email: caroline.swarbrick@manchester.ac.uk

${ }^{1}$ Division of Nursing, Midwifery and Social Work, University of Manchester, UK

${ }^{2}$ Greater Manchester West Mental Health NHS Foundation Trust

${ }^{3}$ Alzheimer Scotland

${ }^{4}$ Pennine Care NHS Foundation Trust

${ }^{5}$ Division of Nursing, Midwifery and Social Work, University of Manchester / Greater Manchester West Mental Health NHS Foundation Trust 


\begin{abstract}
The involvement of people living with dementia in research has traditionally been located in the realms of 'subject' or 'participant'. However, there has been an increase in demand for greater transparency by academic bidding teams (particularly within the UK) in demonstrating how people with a lived experience have been and will be involved in the research process. Located within the ESRC / NIHR-funded Neighbourhoods and Dementia Study (2014-2019), led by The University of Manchester (UK), this paper outlines the development of the $\underline{\text { CO}}-$ researcher $\underline{I N v o l v e m e n t}$ and Engagement in Dementia (COINED) Model, which was co-produced alongside three independent groups of people living with dementia: Open Doors, the Scottish Dementia Working Group and EDUCATE.
\end{abstract}

\title{
Keywords
}

Dementia; Involvement; Engagement; Co-production; Co-research 


\section{Background}

Over the last decade or so within the United Kingdom (UK), research funding councils and charities have demanded greater transparency from academic bidding teams in demonstrating how people with lived experience (of the proposed topic under study) have been, or will be, involved in the research process. This may range from mapping out how people with lived experience have been involved in proposal development to a detailed consideration about future plans for the person's involvement in data collection, data analysis and project dissemination. This is often referred to as Patient and Public Involvement, or PPI for short. Indeed, nowadays, it is not uncommon for those with lived experience to be integral members of academic bidding teams in order to demonstrate an authentic commitment to PPI engagement with Wright, Foster, Amir, Elliott, \& Wilson (2010) viewing such partnerships as a "core component of good research practice" (p. 359).

In advancing such academic / lived experience partnerships, a number of generic frameworks and public agencies have emerged, such as INVOLVE (http://www.invo.org.uk/) which is funded by the UK's National Institute for Health Research (NIHR). Established in 1996, INVOLVE's role is to promote and support public involvement in the UK's National Health Service, as well as in social care and public health research. Subsequently, numerous training programmes have been developed in order to support public involvement, namely within service delivery and care planning domains. As an illustration, the NIHRfunded (Programme Grants for Applied Research) EQUIP Study, 'Enhancing the quality of service user involved care planning in Mental Health Services' (http://www.invo.org.uk/equip/), was recently highlighted nationally as an example of good research practice by both INVOLVE and the National Institute for Health and Care Excellence. Whilst the feasibility and application of programmes such as EQUIP in fields outside of mental health, care planning and service delivery have not yet been established, there are several generic key messages for meaningful user involvement in research: 1) People with lived experience should feel enabled, not disabled, to take part; 2) Support and facilitation should be provided to meet the needs and abilities of the individual, not the condition; and 3) The relationship between academic researchers and those with lived experience should be based on a collaborative and reciprocal partnership.

Set against these key messages, developments within the PPI arena are increasingly important in the field of dementia studies (Harris \& Sterin, 1999; Tanner, 2012), albeit at a slow rate. For example, Alzheimer Europe (2011) set out their principles of research encouraging a change in ideology from research 'on' people living with dementia to research 'alongside' or 'with' people living with dementia. Building on this foundation, the Scottish 
Dementia Working Group (2013) developed their own core principles for involving people living with dementia in research, such as "we want to be valued, and to be kept involved and informed" (core principle 1) and "we are often involved in answering research questions, but we are not often asked about research priorities" (core principle 2). This change in direction has also entered the UK political discourse, first through the Prime Minister's Challenge on Dementia (DH, 2012, p. 5), which identified three key commitments: driving improvements in health and care; creating dementia friendly communities that understand how to help; better research. This inclusive agenda recognised the citizenship of people living with dementia (Bartlett \& O' Connor, 2007). This was further endorsed through the Prime Minister's second Challenge on Dementia (Department of Health $[D H], 2015)$, which highlighted the partnership in dementia research 'between patients, researchers, funders and society' ( $p$. 46).

However, despite this high profile association, Harrison and Johnson (2015) draw attention to the lived experience movement in dementia as being in its infancy. The primary reasons for this, the authors argue, are threefold: 1) people living with dementia have traditionally been positioned as either a 'subject' or 'participant'; 2) there have been a lack of opportunities for people living with dementia to be involved and engaged in research; and 3) the time-consuming and legislative requirements of establishing capacity, obtaining consent and safeguarding anonymity in the research process. As Higgins (2013) and McKeown, Clarke, Ingleton, \& Repper, (2010) have contended, such obstacles are barriers for the person with dementia's inclusivity, egalitarianism and full citizenship in society. Moreover, according to Marjanovic, Robin, Lichten, Harte, MacLure, Parks, Horvath, Côté, Roberge, \& Rashid (2015, p. 81), there remain unanswered questions about how people living with dementia and their carers can "best be involved in dementia research initiatives".

\section{The Neighbourhoods Study: Developing a Co-Research Model}

To try and respond to this dilemma, this article will outline the development of what we have termed a 'CO-researcher INvolvement and Engagement in Dementia' Model, or the COINED Model for short, which has been co-produced with and alongside people living with dementia. The COINED Model was developed during the application stage of the subsequently funded Neighbourhoods and Dementia Study [2014-2019], which is a large, multi-centre international study on neighbourhoods and dementia (Keady, Clark, FergusonColeman, Hellström, Hydén, Pendleton, Reilly, Swarbrick, Ward, \& Young, 2014; www.neighbourhoodsanddementia.org, accessed $1^{\text {st }}$ June 2016). Funded by the Economic and Social Research Council (ESRC) / NIHR, the Neighbourhoods and Dementia Study comprises eight Work Programmes, of which the primary foci is to centralise the vision and 
values of people living with dementia and their carers in research practice; embrace creativity, innovation and shared stories; and empower the experience of people living with dementia, their carers and neighbourhood networks. Work Programme 1: Member Involvement (www.neighbourhoodsanddementia.org/work-programme-1/) has a dual aim: to facilitate the involvement of people living with dementia in all of the Work Programmes as co-researchers and; to co-design and lead a neighbourhoods-focused research project. The term 'co-researcher' reflects a desire to move away from references to 'user' and 'patient and public involvement', towards a more collaborative partnership between groups of people living with dementia, academic researchers and service providers. We will, therefore, use the term 'co-researcher' - whereby 'co-' incorporates collaboration, cooperation and community to further consolidate that partnership.

\section{Methods}

Open Doors (Howorth, Riley, Drummond, \& Keady, 2011), located in Salford, Greater Manchester (UK); EDUCATE (the EEarly ㅁementia Users ㅁo-operative iiming Io Educate; www.educatestockport.org.uk), based in Stockport, Greater Manchester (UK); and the Scottish Dementia Working Group (Scotland, UK) are awareness-raising and informationgiving groups of people living with dementia. All groups led the development of the COINED Model, which was facilitated by the lead author. The groups met independently with the first author acting as a conduit for the exchange of ideas and thoughts. Whilst this was theoretically a 'PPI' activity, the principles of Participatory Action Research (Morgan, Crossley, Stewart, Kirk, Forbes, D'Arcy, Dal Bello-Haas, McBain, O'Connell, Bracken, Kosteniuk, \& Cammer, 2014; O'Sullivan, Hocking, \& Spence, 2014) were adopted, with a focus on "collaborative, equitable partnership in all phases of the research" (Blair, \& Minkler, 2009 , p. 653). Using INVOLVE's generic research cycle (INVOLVE, 2012, p. 40) as a starting point (see figure 1), the remit of discussions was to identify ways in which members of the groups would like to be involved as co-researchers across the research trajectory.

Insert figure 1 about here

\section{Co-Producing the COINED Model}

Framed around the themes outlined in figure 1, group members developed a more comprehensive compendium of themes of co-researcher involvement and engagement (see figure 2). Each component of the Model represents inclusivity, mutual respect and 
empowerment which are at the very core of the Neighbourhoods and Dementia Study agenda (Keady et al., 2014, p. 17).

\author{
Insert figure 2 about here.
}

Underpinning the COINED Model is training and support for co-researchers, which we recommend should be provided for the duration of the research. Group members were insistent that support should be provided from an academic standpoint (Work Programme 8 involves a Wellbeing Service, facilitated by a Clinical Psychologist) in parallel to peer support, either through formal agencies (including dementia support organisations, such as the Alzheimer's Society) or informal peer support network. The voice of people living with dementia is principal to the mode of inquiry as 'experts of experience' and representation must be embedded as a continuous presence throughout the research. In parallel, the importance of peer support in providing a community network is essential in maintaining wellbeing, self-confidence and a sense of security within an ever-changing environment.

An insightful discussion focused on the collection and analysis of data, and more specifically around the level of objectivity expected by the co-researcher and the extent to which someone with lived experience is able to deliver that objectivity. Group members acknowledged the potential risk that the co-researcher may influence the responses given by the participant by sharing their own experiences, inadvertently extending their own peer support discourse. Conversely, however, group members were aware that shared experiences (between the co-researcher and participant) have the potential to enrich the responses given. On balance, group members were aware that the data collected by a coresearcher would inevitably provide different levels of richness, depth and context compared to data collected by an academic researcher. It was noted that this in itself would provide an interesting evaluation at a later stage.

Exploring the data and understanding the meaning of the results were key discussion points, whereby disparity between the collection of data, its presentation in the final report and the lack of transparency was noted as devaluing the role of people living with dementia in research (both as co-researchers and as participants). 'Accessibility' featured at the very heart of effective communication, particularly in terms of language and terminology used. Knowledge exchange was regarded as fundamental to the advancement of learning for all. There was a general feeling that the process of translating research into practice was often 
disparate and fragmented. Subsequently, group members advocated the involvement of people living with dementia in presenting research findings alongside academic colleagues in ways which would be creative, accessible and meaningful to all.

Several members of the groups (who also had an academic background) raised the issue of 'impact'. Given the different meanings and interpretations of the term, we agreed that in the context of the COINED Model, we will use the term 'impact' to refer to the effectiveness of the research or the effectiveness of the involvement of people living with dementia as coresearchers. Discussions extended to narrative of 'evaluation', which was regarded as an integral mechanism of the research in 'measuring' impact, which was necessary to ensure that we are 'getting it right'. It was felt that the processes and outcomes of any evaluation would be crucial to our learning and should be embedded within further decision-making. Thus, our learning from the research findings will help to identify, shape and frame further research priorities. Group members appreciated the ongoing shift in research priorities to meet the needs of the changing landscape of dementia care and fluctuating needs of people affected by dementia. Involvement in future work was regarded as pivotal in positioning people living with dementia at the centre of research in the context of collaboration and focus.

\section{Discussion}

Whilst discussions in the wider literature focus on whether people living with dementia [as co-researchers] are able to engage in ways that are 'meaningful' to the research process (Tanner, 2012), our approach is to ensure that co-researcher involvement is, first and foremost, meaningful for the individuals themselves, thus respecting and empowering the personhood of people living with dementia (Kitwood, 1997). One of the key messages of the Model was to ensure that its implementation allows for creative methods and expressive output and should not be constrained by traditional research methods and processes. For example, Lee and Adams (2011), Capstick (2011) and Bartlett (2012) offer a collection of visual methods to engage co-researchers in the data collection domain of the research process.

The involvement of people living with dementia as co-researchers is not without its ethical debates. Particularly within the remit of data collection, analysis and dissemination (see figure 2), anonymity and participant confidentiality must be ensured. Whilst academic researchers in England are bound by the Research Governance Framework for Health and Social Care (DH, 2005), there are no parallel frameworks for co-researchers and to our 
knowledge, this issue has not been addressed in the literature. Therefore, the need to formalise the expectations and responsibilities of the co-researchers is a natural next step. The development of the COINED Model has identified ways in which people living with dementia have expressed their wishes to be involved as co-researchers across the research process. The COINED Model is currently being piloted in the Neighbourhoods and Dementia Study with the necessary ethical permissions having been sought. In order to assess its application, we plan to evaluate the implementation of the COINED Model towards the end of the Study during 2018-2019.

\section{Declaration of Conflicting Interests}

The authors declared no potential conflicts of interest with respect to the research, authorship, and / or publication of this article.

\section{Acknowledgements}

The support of the Economic and Social Research Council (ESRC) and National Institute for Health Research (NIHR) is gratefully acknowledged. This work forms part of the ESRC I NIHR Neighbourhoods and Dementia mixed methods study [www.neighbourhoodsanddementia.org], Work Programme 1: Member Involvement.

\section{References}

Alzheimer Europe. (2011). The ethics of dementia research report. Luxembourg: Alzheimer Europe.

Bartlett, R. (2012). Modifying the diary interview method to research the lives of people with dementia. Qualitative Health Research, 22(12), 1717-1726.

Bartlett, R. \& O' Connor, D. (2007). From personhood to citizenship: Broadening the lens for dementia practice and research. Journal of Aging Studies, 21(2), 107-118.

Blair, T. \& Minkler, M. (2009). Participatory action research with older adults: key principles in practice. The Gerontologist, 49(5), 651-662.

Capstick, A. (2011). Travels with a flipcam: bringing the community to people with dementia in a day care setting through visual technology. Visual Studies, 26(2), 142-147.

Department of Health. (2015). Prime Minister's Challenge on Dementia 2020. London, UK: $\mathrm{DH}$. 
Department of Health. (2012). Prime Minister's challenge on dementia. Delivering major improvements in dementia care and research by 2015. London, UK: DH.

Department of Health. (2005). Research governance framework for health and social care. London, UK: DH.

Harris, P., \& Sterin, G. (1999). Insider's perspective: Defining and preserving the self in dementia. Journal of Mental Health and Aging, 5(3), 241-256.

Harrison, D., \& Johnson, M. (2015). Living well with dementia. A participant and engagement programme for people with dementia and their carers. Retrieved from

http://www.nemhdu.org.uk/silo/files/living-well-with-dementia-evaluation-report.pdf .

Higgins, P. (2013). Involving people with dementia in research. Nursing Times, 109(28), 20 23.

Howorth, M., Riley, C., Drummond, G., and Keady, J. (2011). The Open Doors Network: a pioneering scheme. Journal of Dementia Care, 19(3), 20-21.

INVOLVE. (2012). Briefing notes for researchers: public involvement in NHS, public health and social care research. Eastleigh, England: INVOLVE.

Keady, J., Clark, A., Ferguson-Coleman, E., Hellström, I., Hydén, L-C., Pendleton, N., Reilly, S., Swarbrick, C., Ward, R., \& Young, A. (2014). Neighbourhoods and Dementia. Journal of Dementia Care, 22(6), 16-17.

Kitwood, T. (1997). Dementia reconsidered. The person comes first. Buckingham, England: Open University Press.

Lee, H., \& Adams, T. (2011). Creative approaches in dementia care. Basingstoke, England: Macmillan Publishers Ltd.

Marjanovic, S., Robin, E., Lichten, C., Harte, E., MacLure, C., Parks S,. ...Rashid, M. (2015). A Review of the Dementia Research Landscape and Workforce Capacity in the United Kingdom. Cambridge, UK: RAND. 
McKeown, J., Clarke, A., Ingleton, C., \& Repper, J. (2010). Actively involving people with dementia in qualitative research. Journal of Clinical Nursing, 19, 1935-1943.

Morgan, D., Crossley, M., Stewart, N., Kirk, A., Forbes, D., D’Arcy, C., ...Cammer, A. (2014). Evolution of a community-based participatory approach in a rural and remote dementia care research program. Progress in Community Health Partnerships: Research, Education and Practice, 8(3), 337-345.

O'Sullivan, G., Hocking, C. \& Spence, D. (2014). Action research: changing history for people living with dementia in New Zealand. Action Research, 12(1), 19-35.

Tanner, D. (2012). Co-research with older people with dementia: experience and reflections. Journal of Mental Health, 21(3), 296-306.

The Scottish Dementia Working Group and The University of Edinburgh. (2013). Core principles for involving people with dementia in research: innovative practice. Dementia: the international journal of social research and practice, 13(5): 680-685.

Wright, D., Foster, C., Amir, Z., Elliott, J., \& Wilson, R. (2010). Critical appraisal guidelines for assessing the quality and impact of user involvement in research. Health Expectations, 13, 359-368.

\section{Author Biographies}

Caroline Swarbrick (corresponding author) is a Research Fellow in the Dementia and Ageing Research Team at The University of Manchester. With a passion for working alongside people living with dementia as co-researchers, she is driving forward the empowerment agenda through the facilitation of numerous co-researcher-led projects.

Open Doors is a support service facilitated by a person living with dementia (employed through the NHS), based in Salford, Greater Manchester (UK). Located within Greater Manchester West Mental Health NHS Foundation Trust, Open Doors provides a friendship and support network for people living with dementia, including a dementia café and book club, as well as participating in local service planning and design.

The Scottish Dementia Working Group are a national awareness-raising and campaigning group, and an independent voice of people living with dementia. Affiliated to Alzheimer Scotland, the Scottish Dementia Working Group strive to improve societal attitudes towards 
people living with dementia as well as influence policy in order to improve services for people living with dementia.

EDUCATE is an awareness-raising group of people living with dementia, based in Stockport, Greater Manchester (UK). On both a local and national level, group members share their experiences of living with dementia, through talks and presentations and are involved in a wide range of initiatives. EDUCATE is supported by Pennine Care NHS Foundation Trust and Stockport Council.

Katie Davis is a registered nurse with a background in working with people with dementia in the NHS and in the third sector. Katie is currently undertaking a full-time PhD in Nursing at The University of Manchester as part of the 'Neighbourhoods and Dementia' study. She plans to work collaboratively with people with dementia on her doctoral project.

John Keady is a Professor of Mental Health Nursing and Older People at The University of Manchester, UK and a Senior Fellow at the NIHR School of Social Care Research. He is founding and co-editor of Dementia: the international journal of social research and practice. 
Figure 1. INVOLVE's research cycle (2012, p.40).

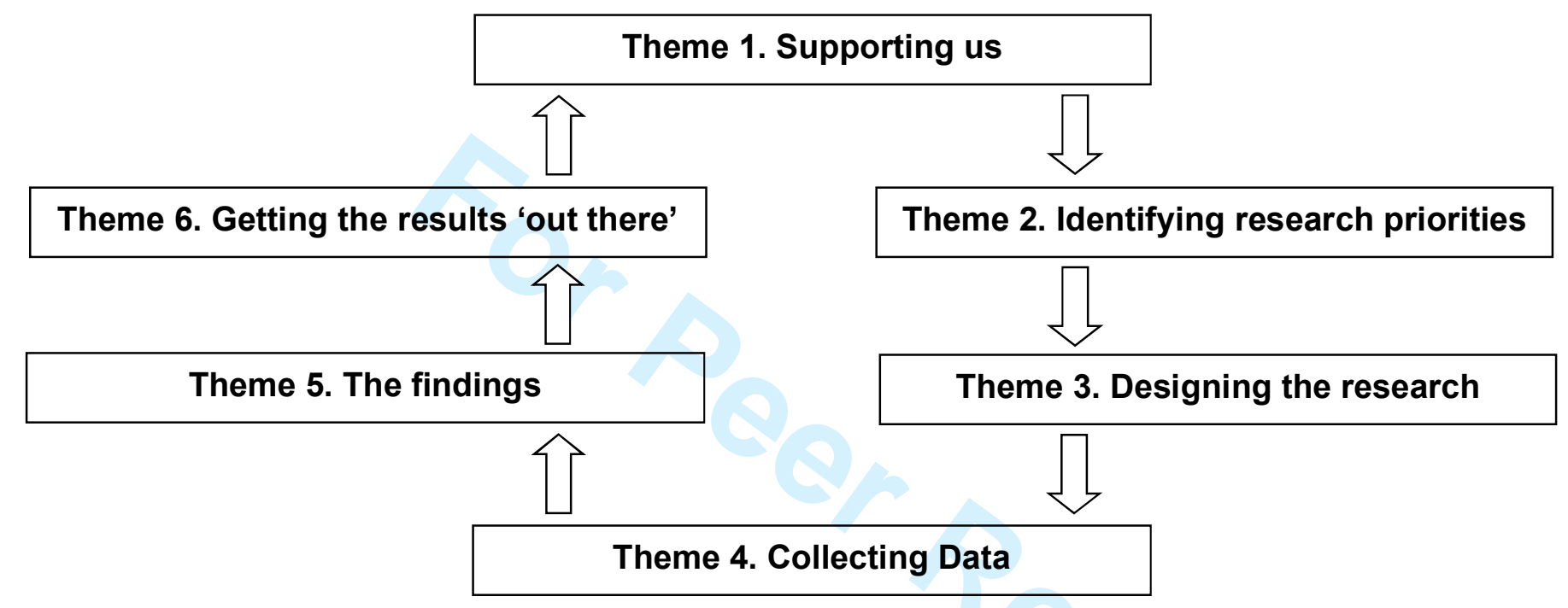


Figure 2. The CO-researcher INvolvement and Engagement in Dementia (COINED) Model.

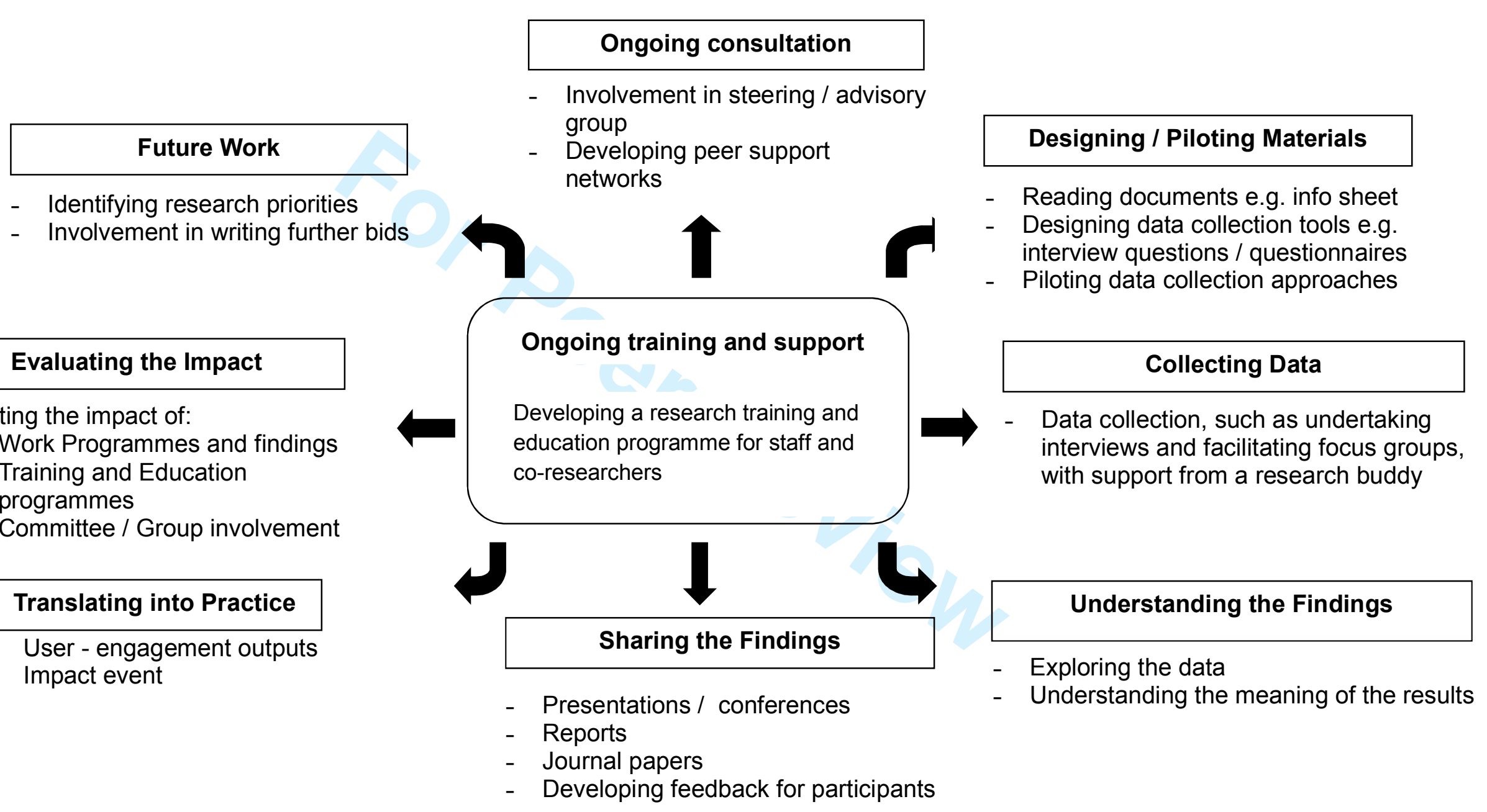

